\title{
OBESITY, EATING BEHAVIOR AND PHYSICAL ACTIVITY DURING COVID-19 LOCKDOWN: A STUDY OF INDIAN TEENAGERS
}

\author{
Madiha Khan ${ }^{1 *}$, ${ }^{2}$ Maneeza Khan, Sabiha $\operatorname{Khan}^{3}$ \& Gausal A. Khan ${ }^{4}$ \\ 1The Heritage School, Kolkata, India. \\ ${ }^{2,3}$ Department of Physiology \& Physiotherapy, College of Medicine, Nursing \& Health Sciences \\ Fiji National University, Suva, Fiji Islands. \\ ${ }^{4}$ School of Public Health and Primary Care, College of Medicine \\ Nursing and Health Sciences, Fiji National University, Suva, Fiji
}

\begin{abstract}
Lockdowns measures including closure of educational institutions due to COVID-19 may affect youth's activity patterns, psychological stress and obesity status. This is the first kind of study in India on the basis of a large number of teenage subjects from the COVID-19 Impact on Lifestyle Changes. Through an online questionnaire, 144 participants from high schools, aged 10-19 years, voluntarily reported their lifestyles and weight, basal metabolic rate (BMI) status in between 19th July to 12th August 2020 (before and after lockdown). Our data suggest that teenagers having prevalence of significant weight $(49.6 \pm 15.5$ to $52.1 \pm 15.2$ Kgs $p<0.001)$ and BMI $(21.0 \pm 1.2$ to

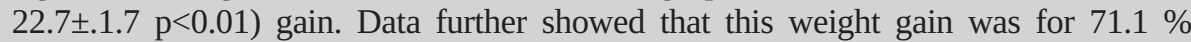
teenagers and BMI 67.2\% subjects. Also, significant decreases were seen in the frequency of engaging in active physical activity, and leisure-time walking, while significant increases were observed in the average sedentary time during weekdays and weekends. Our findings would serve as important evidence for making strategies to counteract or reverse the lockdown effects on youths' obesity.
\end{abstract}

\section{Keywords}

Exercise, Junk food, Obesity, teenagers, Lifestyle, Diet, Exercise, Sleep, COVID-19.

\section{Introduction}

The COVID-19 pandemic has compelled nearly everyone to redefine their daily lifestyle-related habits (1). In April 2020, more than 430000 people perished due to the coronavirus in India. (2). On March $21^{\text {st }}$, the Indian government imposed strict lockdown measures to curb the spread of the virus (3). World Obesity federation reported that countries where more than half the population is obese, have had ten times higher death rates from COVID-19 than the countries where the obese population is lesser relatively (4). These findings emphasize on the need to address the rising obesity epidemic also, alongside the COVID-19 pandemic. Obesity in India has reached epidemic proportions in the $21^{\text {st }}$ century, with morbid obesity affecting 5\% of the country's population (5). As unhealthy processed junk food is becoming more accessible, the average caloric intake per individual among more middle class and high-income individuals are skyrocketing (6). The intakes have further skyrocketed during the lockdown due to a sudden and radical shift in lifestyle of the population (7). Physical distancing and selfisolation has caused less socialization and has strongly impacted citizens' lives, affecting in particular eating habits and everyday behaviors (7).

Drastic lifestyle changes have occurred due to two major influences: (a) staying at home [due to digital-education, smart working, limitation of outdoors and in-gym physical activity] and (b) stockpiling food, due to the restriction in grocery shopping. As a result, the lack of physical contact and disruption of work routine produced by the quarantine may result in boredom, which is linked to a higher energy intake (8). In addition to boredom, hearing or reading about the pandemic's bleak state via the media can be upsetting. When compared to general adults, the youth population has been shown to be more vulnerable to changes in lifestyle and eating patterns, which could be seen during the COVID-19 epidemic. Despite the fact that India's lockdown has been removed, state 
institutions continue to encourage preserving social distance, limiting outside activities, and limiting population mobility. For fear of a third wave epidemic, some Indian institutions remained closed until May, and others even required students not to return for the semester. When compared to general adults, the youth population has been shown to be more vulnerable to changes in lifestyle and eating patterns, which could be seen during the COVID-19 epidemic. Despite the fact that India's lockdown has been removed, state institutions continue to encourage preserving social distance, limiting outside activities, and limiting population mobility. For fear of a third wave pandemic, some Indian institutions remained closed until May, and others even required students not to return for the semester (9). Many kids were obliged to stay at home for extended periods of time as a result of these circumstances. (1011). These foods, which are mostly high in simple carbs, can help to relieve stress by promoting serotonin production, which has a good influence on mood. Beyond a chronic state of inflammation that has been shown to increase the risk for more severe COVID-19 complications, this food craving effect of carbohydrates is proportional to the glycemic index of foods, which is associated with an increased risk of developing obesity and cardiovascular diseases.

Maintaining a healthy and diverse diet, as well as regular physical activity, may be hampered by this new condition. For example, limited access to daily grocery shopping may lead to reduce the consumption of fresh foods, especially fruit, vegetables and fish, in favor of highly processed ones, such as convenience foods, junk foods, snacks, and ready-to-eat cereals, which tend to be high in fats, sugars, and salt. Moreover, psychological and emotional responses to the COVID-19 outbreak may increase the risk of developing dysfunctional eating behaviors (12-13). It is well known how the experience of negative emotions can lead to overeating, the so-called “emotional eating” (14-15). Several studies related to obesity in lockdown have already been conducted in some countries.

A study of 41 children and adolescents with obesity in Italy found that compared to data collected in 2019, three weeks into social lockdown participants reported less time exercising and increased consumption of 'unhealthy' junk foods (16). In a UK study, adults with obesity were more likely to report that they believed that a limited number of behaviors typically protective against weight gain (e.g., physical activity) had declined compared to before lockdown (17), although neither of these studies included validated or widely used measures of physical activity, diet quality or overeating collected during social lockdown. Moreover, the importance of studying weight-related behaviors and understanding barriers to weight management during the COVID-19 crisis is highlighted by higher BMI being associated with an increased risk of hospitalization and death from coronavirus (18-19).

The aim of this study was to examine perceived changes in a variety of weight-related behaviors in a large sample of Indian teenagers during social lockdown (before vs. after), to examine if there were any common barriers to weight management as a result of the COVID-19 crisis. Furthermore, we investigated characteristics linked with and potentially contributing to reduced levels of physical activity and less healthy eating during the COVID-19 crisis by evaluating physical activity levels, diet quality, and problematic overeating during lockdown. Because people with obesity may be disproportionately affected by lockdown measures (for example, due to risk-based shielding measures and limited access to weight management services), the goal of this study was to see how much higher BMI is linked to weight management-related barriers and behaviours during COVID19 lockdown. We hypothesized that greater BMI would be linked to unfavorable changes in weight-related behaviors and additional weight-management hurdles as a result of the COVID-19 crisis.

\section{METHODOLOGY}

\section{Study design and data collection}

A total of 144 eligible teenagers were included in this study. Teenagers (ages $10-19$ years). The average age of the participants was $19 \cdot 8 \pm 2 \cdot 3$ years old (Table 1 ). The majority of them were female (52.7\%), from Uttar Pradesh (36.1\%), a nuclear family (62.5\%) and from the western region (87.9\%). The most common annual household income category is below Rs. 12,000. None of the high school students from the northeastern and central regions participated in the survey. Between males and girls, there were no significant variations in age or ethnicity.

There remain significant changes of youths' weekly frequency of major food intake after lockdown, with differences between sex and across educational levels in some dietary types.

A Google forms survey was carried out in India from $19^{\text {th }}$ July to $12^{\text {th }}$ August 2020. The subjects were recruited using a snowball sampling method by distributing the survey among several social media groups such as Instagram, Facebook and WhatsApp. All recruited participants have voluntarily reported their basic socio-demographic information and routine lifestyles in the month immediately before the COVID-19 lockdown in India (March 2020, hereafter referred to as before lockdown), during lockdown (July 2020, hereafter referred to as during lockdown) and after the lockdown was lifted (July 2021 hereafter referred to as after lockdown). An informed consent notice was highlighted on the bottom page of the questionnaire, and only those teenagers who consented to have their data used and clicked the 'submit' button were taken into consideration while doing the analysis. The questionnaire was designed to be completed online anonymously. 
Table 1: Questionnaires' and responses N=144.

\begin{tabular}{|c|c|c|}
\hline Variable & Number & percentage \\
\hline \multicolumn{3}{|l|}{ Age } \\
\hline $10-15$ & 82 & 56.9 \\
\hline $16-19$ & 62 & 43.1 \\
\hline \multicolumn{3}{|l|}{ Gender } \\
\hline Male & 68 & 47.3 \\
\hline Female & 76 & 52.7 \\
\hline \multicolumn{3}{|l|}{ Which state are you from? } \\
\hline Uttar Pradesh & 52 & 36.1 \\
\hline West Bengal & 44 & 30.6 \\
\hline Others & 48 & 33.3 \\
\hline \multicolumn{3}{|l|}{ Family status } \\
\hline Nuclear & 90 & 62.5 \\
\hline Extended & 54 & 37.5 \\
\hline \multicolumn{3}{|l|}{ Family income (in month) } \\
\hline$<20$ & 44 & 30.6 \\
\hline 20-60k & 19 & 13.2 \\
\hline $60-100 \mathrm{k}$ & 36 & 25.0 \\
\hline$>100 \mathrm{~K}$ & 37 & 25.7 \\
\hline \multicolumn{3}{|l|}{ Weight: } \\
\hline What was your weight pre lockdown? & 49 & 48.7 \\
\hline What was your weight post lockdown & 52.1 & 51.2 \\
\hline \multicolumn{3}{|l|}{ BMI } \\
\hline Pre lockdown & 21.4 & 49.65 \\
\hline Post lockdown & 21.7 & 50.35 \\
\hline \multicolumn{3}{|c|}{ Roughly how many hours are you sleeping at night? } \\
\hline $3-5$ & 12 & 8.3 \\
\hline $6-8$ & 103 & 71.5 \\
\hline $9-11$ & 29 & 20.1 \\
\hline \multicolumn{3}{|c|}{ Do you have any health problems/ existing disease related to obesity } \\
\hline None & 89 & 61.8 \\
\hline Respiratory & 10 & 6.9 \\
\hline NCD & 19 & 13.2 \\
\hline Other & 26 & 18.1 \\
\hline \multicolumn{3}{|c|}{ I have eaten a healthy and balanced diet during lockdown } \\
\hline 1-2 times per week & 29 & 20.1 \\
\hline 3-4 times per week & 31 & 21.5 \\
\hline$>4$ times per week & 44 & 30.6 \\
\hline Not at all & 40 & 27.8 \\
\hline \multicolumn{3}{|c|}{ During lockdown, I have eaten junk food } \\
\hline 1-2 times per week & 59 & 41.0 \\
\hline 3-4 times per week & 35 & 24.3 \\
\hline$>4$ times per week & 13 & 9.0 \\
\hline Not at all & 37 & 25.7 \\
\hline \multicolumn{3}{|l|}{ During lockdown, I have exercised } \\
\hline 1-2 times per week & 23 & 16.0 \\
\hline 3-4 times per week & 33 & 22.9 \\
\hline$>4$ times per week & 76 & 52.8 \\
\hline Not at all & 12 & 8.3 \\
\hline \multicolumn{3}{|c|}{ How many hours approximately a day have you exercised during lockdown? } \\
\hline$<1 \mathrm{hr}$ & 42 & 29.2 \\
\hline $1-2$ hrs & 75 & 52.1 \\
\hline 3-4 hrs & 10 & 6.9 \\
\hline$>4$ hrs & 7 & 4.9 \\
\hline Not at all & 10 & 6.9 \\
\hline
\end{tabular}




\section{Inclusion and exclusion criterion}

The participants having any pre-existing medical condition (Diabetes, anemia, cancer or any other life threatening diseases are excluded from the study.

\section{Statistical analysis}

Continuous data are presented as means and standard deviations (SD) categorical data are presented as absolute and relative (\%) frequencies. Chi-squared, t-tests were used to determine differences between groups. A p-value $<0.05$ was considered as significant. All analysis was carried out using SPSS version 25.

\section{RESULTS}

Socio-demographic profile of study participants

144 teenagers ranging from 10 - 19 years participated in the study. The majority of participants were in the age group of $10-15$ (56.9\%). 68 males (47.3\%) and 78 females (52.7\%) participated in the survey. Demographically, 52 participants (36.1\%) were from Uttar Pradesh, 44 (30.6\%) from West Bengal, and 48 (33.3\%) from other states of India. Noticeably, 90 participants $(62.3 \%)$ belong to the nuclear family compared to 54 participants who belong to the extended family (37.5\%). In terms of financial wellbeing, 44 participants $(30.6 \%)$ of the participants had a monthly income of less than 20000 INR

Table 2: Profile of study participants $(n=144)$

\begin{tabular}{|c|c|c|c|}
\hline S. No. & Socio-demographic variable & Frequency $(\mathrm{N}=144)$ & Percentage (\%) \\
\hline 1. & $\begin{array}{l}\text { Age (in years) } \\
10-15 \\
16-19\end{array}$ & $\begin{array}{l}82 \\
62\end{array}$ & $\begin{array}{l}56.9 \\
43.1\end{array}$ \\
\hline 2. & $\begin{array}{l}\text { Gender } \\
\text { Male } \\
\text { Female }\end{array}$ & $\begin{array}{l}68 \\
76\end{array}$ & $\begin{array}{l}47.3 \\
52.7\end{array}$ \\
\hline 3. & $\begin{array}{l}\text { Indian State } \\
\text { Uttar Pradesh } \\
\text { West Bengal } \\
\text { Others }\end{array}$ & $\begin{array}{l}52 \\
44 \\
48\end{array}$ & $\begin{array}{l}36.1 \\
30.6 \\
33.3\end{array}$ \\
\hline 4. & $\begin{array}{l}\text { Family status } \\
\text { Nuclear } \\
\text { Extended }\end{array}$ & $\begin{array}{l}90 \\
65\end{array}$ & $\begin{array}{l}62.5 \\
37.5\end{array}$ \\
\hline 5. & $\begin{array}{l}\text { Family income/month (INR) } \\
<20 \mathrm{k} \\
20-60 \mathrm{k} \\
60-100 \mathrm{k} \\
>100 \mathrm{~K} \\
\text { Not known }\end{array}$ & $\begin{array}{l}44 \\
19 \\
36 \\
37 \\
08\end{array}$ & $\begin{array}{c}30.6 \\
13.2 \\
25.0 \\
25.7 \\
5.6\end{array}$ \\
\hline
\end{tabular}

COVID-19 lockdown affects the Weight and BMI of the teenagers

A study conducted in the Chinese adult population (22) shows an increasing trend of weight and BMI due to lockdown. Similarly, Chopra et al's study on Indian adults found that their eating patterns changed adversely during lockdown leading to weight gain (23).
However, our data in Indian teenagers showed that lockdown significantly improved the weight gain as well as BMI of both male and female teenagers (Table 3). Our data also showed a similar trend as found by others. Our data father suggest that $71.1 \%$ of the subject gained weight in comparison to $67.2 \%$ of the subjects' increased BMI.

(Table 3).

Table 3: Weight and BMI changes in Indian teenagers ( $n=144)$.

\begin{tabular}{|l|c|c|c|c|c|c|c|c|c|c|}
\hline & \multicolumn{2}{|c|}{ Female } & \multicolumn{2}{c|}{ Male } & \multicolumn{2}{c|}{ Overall } & & \\
\hline $\begin{array}{c}\text { pre } \\
\text { lockdown } \\
\text { weight }\end{array}$ & $\begin{array}{c}\text { pre } \\
\text { lockdown } \\
\text { weight }\end{array}$ & P value & $\begin{array}{c}\text { pre } \\
\text { lockdown } \\
\text { weight }\end{array}$ & $\begin{array}{c}\text { pre } \\
\text { lockdown } \\
\text { weight }\end{array}$ & P value & $\begin{array}{c}\text { pre } \\
\text { lockdown } \\
\text { weight }\end{array}$ & $\begin{array}{c}\text { pre } \\
\text { lockdown } \\
\text { weight }\end{array}$ & P value & $\%$ Change \\
\hline Weight & $45.1 \pm 11.8$ & $47.1 \pm 11.4$ & $<0.001$ & $54.6 \pm 17.5$ & $57.7 \pm 17.0$ & $<0.001$ & $49.6 \pm 15.5$ & $52.1 \pm 15.2$ & $<0.001$ & 71.1 \\
\hline BMI & $19.1 \pm 5.1$ & $20.9 \pm 1.6$ & $<0.01$ & $23.0 \pm 2.0$ & $24.5 \pm 2.7$ & $<0.01$ & $21.0 \pm 1.2$ & $22.7 \pm .1 .7$ & $<0.01$ & 67.2 \\
\hline
\end{tabular}




\section{DISCUSSION}

The COVID-19 pandemic has severely affected people's everyday routines in India. Initially, the country's lockdown had ramifications in terms of food availability and use, putting a strain on normal food-related behaviour (13). Furthermore, in order to combat the spread of COVID-19, gyms, fitness facilities, and limitations on visiting parks, playgrounds, and other public places have been closed, limiting access to numerous forms of physical activity (1415). Furthermore, confinement could have influenced sleeping patterns (5). Deviation from a healthy lifestyle can increase the chance of developing obesity and aggravate the condition of individuals who already have it (6). In light of the aforementioned concerns, it is crucial to determine the extent to which this pandemic and its associated restrictions have affected people's lifestyle-related behaviour, such as food habits, physical activity, and sleep patterns, particularly among teenagers.

This study assessed weight gain and BMI variations among Indian teenagers as a result of lockdown, as well as changes in eating patterns and physical activity. The questionnaire's dietrelated questions look at how often people eat main meals, how often they snack, how much they eat healthy foods like whole grains, fruits and vegetables, eggs, and nuts, as well as how much they eat unhealthy foods like fried food, junk food, and sugar-sweetened products.

In addition, there are only a few elements dedicated to analysing immunity-boosting food intake. In addition, some physical activity questions examine the participants' participation in aerobic exercise, household-related tasks, sitting time, and screen time. Throughout the pandemic, experts from all around the world have shown a significant interest in assessing people's lifestyle-related behaviour. The self-developed questionnaire utilised on the Polish population, on the other hand, examines solely people's dietary choices and habits during the COVID-19 epidemic (16). Furthermore, the tool's reliability and validity are dubious. The questionnaire employed in another study was not well-designed and applicable to Indian citizens.

Increased screen time was connected with alcohol and sweets during the COVID-19 pandemic, depending on the screen device. Increased television and cell phone time were linked to higher sweetened food intake and a desire to consume alcoholic drinks, whereas increased computer time was linked to lower alcohol and sweetened food consumption. For further examination of hazardous behaviours caused by the epidemic, increasing screen time spent on the television and cell phone must be taken into account.

The crucial findings of the survey divulge certain trends in eating habits and physical activity behavior among teenagers. Our survey further showed the increasing trend of weight gain and BMI during the lockdown. This might be due to less physical activity and a sedentary lifestyle. Obviously, psychological behavior and mindset are also other important factors that make teenagers more inclined towards a sedentary lifestyle, leading to weight gain.
This is the first pan-India study of teenagers, with the goal of recruiting a representative sample for data collection via a pre-validated questionnaire to investigate the impact of COVID-19 on lifestyle-related behaviors. Some of the study's shortcomings include the possibility of reporting bias owing to the e-survey, and the validity of responses, which is a common concern with online surveys.

\section{CONCLUSION}

In conclusion, the preventative measures enacted/adopted to control COVID - 19 had a mixed influence on lifestylerelated behavior, with considerable improvements in regular meal consumption patterns and healthy eating behavior, as well as a reduction in unhealthy food intake, as positive indicators. Therefore, this study delineated the fact that continuous inaction among teenagers also improves weight gain which leads to a sedentary lifestyle and cardiovascular diseases in the future. Therefore, physical activities are the main factor to keep the teenage population healthy.

\section{REFERENCES}

1. Husain W, Ashkanani F. Does COVID-19 change dietary habits and lifestyle behaviours in Kuwait: a community-based cross-sectional study. Environmental health and preventive medicine. 2020 Dec; 25(1):1-3.

2. Mao Y, Jiang S, Nametz^ D, Lin Y, Hack J, Hensley J, Monaghan R, Gutenbrunner T. Data-driven analytical models of COVID-2019 for epidemic prediction, clinical diagnosis, policy effectiveness and contact tracing: a survey. arXiv preprint arXiv:2006.13994. 2020 Jun 24.

3. Ambikapathy B, Krishnamurthy K. Mathematical modelling to assess the impact of lockdown on COVID19 transmission in India: model development and validation. JMIR public health and surveillance. 2020 May 7;6(2):e19368.

4. Michalakis K, Panagiotou G, Ilias I, Pazaitou Panayiotou K. Obesity and COVID 19: A jigsaw puzzle with still missing pieces. Clinical Obesity. 2021 Feb;11(1):e12420.

5. Gothankar JS, Patil RS. Prevalence of obesity and its associated co morbidities amongst adults. Natl J Community Med. 2011 Jul;2(2):221-4.

6. Kearney J. Food consumption trends and drivers. Philosophical transactions of the royal society B: biological sciences. 2010 Sep 27; 365(1554):2793-807.

7. Di Renzo L, Gualtieri P, Pivari F, Soldati L, Attinà A, Cinelli G, Leggeri C, Caparello G, Barrea L, Scerbo F, Esposito E. Eating habits and lifestyle changes during COVID-19 lockdown: an Italian survey. Journal of translational medicine. 2020 Dec; 18:1-5.

8. Moynihan AB, Van Tilburg WA, Igou ER, Wisman A, Donnelly AE, Mulcaire JB. Eaten up by boredom: consuming food to escape awareness of the bored self. Frontiers in psychology. 2015 Apr 1; 6:369.

9. Rundle AG, Park Y, Herbstman JB, Kinsey EW, Wang YC. COVID-19 related school closings and risk 
of weight gain among children. Obesity (Silver Spring, Md.). 2020, Jun, 28, 6:1008.

10. Rodríguez-Martín BC, Meule A. Food craving: new contributions on its assessment, moderators, and consequences. Frontiers in psychology. 2015 Jan 22; $6: 21$.

11. Yılmaz C, Gökmen V. Neuroactive compounds in foods: Occurrence, mechanism and potential health effects. Food Research International. 2020 Feb 1; 128:108744.

12. Ma Y, Ratnasabapathy R, Gardiner J. Carbohydrate Craving-not everything is sweet. Current opinion in clinical nutrition and metabolic care. 2017 Jul;20; 4:261.

13. Muscogiuri G, Pugliese G, Barrea L, Savastano S, Colao A. Commentary: obesity: the "Achilles heel” for COVID-19? Metabolism-Clinical and Experimental. 2020 Jul 1; 108.

14. Wu C, Chen X, Cai Y, Zhou X, Xu S, Huang H, Zhang L, Zhou X, Du C, Zhang Y, Song J. Risk factors associated with acute respiratory distress syndrome and death in patients with coronavirus disease 2019 pneumonia in Wuhan, China. JAMA internal medicine. 2020 Jul 1; 180(7):934-43.

15. Pietrobelli A, Pecoraro L, Ferruzzi A, Heo M, Faith M, Zoller T, Antoniazzi F, Piacentini G, Fearnbach SN, Heymsfield SB. Effects of COVID 19 lockdown on lifestyle behaviors in children with obesity living in Verona, Italy: a longitudinal study. Obesity. 2020 Aug; 28(8):1382-5.

16. Robinson E, Gillespie S, Jones A. Weight related lifestyle behaviours and the COVID 19 crisis: An online survey study of UK adults during social lockdown. Obesity science \& practice. 2020 Dec; 6(6):735-40.

17. Garg S, Kim L, Whitaker M, O'Halloran A, Cummings C, Holstein R, Prill M, Chai SJ, Kirley
PD, Alden NB, Kawasaki B. Hospitalization rates and characteristics of patients hospitalized with laboratoryconfirmed coronavirus disease 2019-COVID-NET, 14 States, March 1-30, 2020. Morbidity and mortality weekly report. 2020 Apr 17; 69(15):458.

18. Klang E, Kassim G, Soffer S, Freeman R, Levin MA, Reich DL. Severe obesity as an independent risk factor for COVID 19 mortality in hospitalized patients younger than 50. Obesity. 2020 Sep; 28(9):1595-9.

19. Bhutani S, Cooper JA. COVID-19-related home confinement in adults: Weight gain risks and opportunities. Obesity. 2020 Sep 1; 28(9):1576-7.

20. IPAQ Research Committee. Guidelines for data processing and analysis of the International Physical Activity Questionnaire (IPAQ)-short and long forms. http://www. ipaq. ki. Se/scoring. 2005.

21. Green MA, Li J, Relton C, Strong M, Kearns B, Wu M, Bissell P, Blackburn J, Cooper C, Goyder E, Loban A. Cohort profile: the Yorkshire health study. International Journal of Epidemiology. 2016 Jun 1; 45(3):707-12.

22. Jia P, Zhang L, Yu W, Yu B, Liu M, Zhang D, Yang S. Impact of COVID-19 lockdown on activity patterns and weight status among youths in China: the COVID-19 Impact on Lifestyle Change Survey (COINLICS). International Journal of Obesity. 2021 Mar;45(3):6959.

23. Chopra S, Ranjan P, Singh V, Kumar S, Arora M, Hasan MS, Kasiraj R, Kaur D, Vikram NK, Malhotra A, Kumari A. Impact of COVID-19 on lifestyle-related behaviours-a cross-sectional audit of responses from nine hundred and ninety-five participants from India. Diabetes \& Metabolic Syndrome: Clinical Research \& Reviews. 2020 Nov 1;14(6):2021-30. 